\title{
Coinfection with Mycoplasma Pneumoniae and Chlamydia Pneumoniae in Ruptured Plaques Associated with Acute Myocardial Infarction
}

\author{
Maria de Lourdes Higuchi, Marcia Martins Reis, Nádia Vieira Sambiase, \\ Suely Aparecida Pinheiro Palomino, Jussara Bianchi Castelli, Paulo Sampaio Gutierrez, \\ Vera Demarchi Aiello, J osé Antonio Franchini Ramires
}

São Paulo, SP - Brazil

\begin{abstract}
Objective - To study atheromas, Mycoplasma pneumoniae (M. pneumoniae), and Chlamydia pneumoniae (C. pneumoniae).

Methods-C. pneumoniae was studied with immunohistochemistry and M. pneumoniae with in situ hybridization (ISH), in segments of coronary arteries (SCA) as follows: group A - thrombosed ruptured plaques (TRP) of 23 patients who died due to acute myocardial infarction (AMI); group B-23 nonruptured plaques (NRP) of group A patients; group $C-N R P$ of 11 coronary patients who did not die due to AMI; and group D-11 SCA from patients with dilated cardiomyopathy or Chagas' disease without atherosclerosis.
\end{abstract}

Results - The mean number of C. pneumoniae ${ }^{+}$cells/ 400x in groups $A, B, C$, and $D$ was, respectively, 3.3 \pm 3.6 ; $1.0 \pm 1.3 ; 1.2 \pm 2.4$; and $0.4 \pm 0.3$; and the percentage of $\mathrm{M}$. pneumoniae area was, respectively, $3.9 \pm 3.5 ; 1.5 \pm 1.6$; $0.9 \pm 0.9$; and $0.4 \pm 0.2$. More M. pneumoniae and C. pneumoniae were found in of group A than in group $B(P<0.01)$. Good correlation was seen between the area of the vessel and the M. pneumoniae area in the plaque $(r=0.46$; $P=0.001)$ and between $\mathrm{C}$. pneumoniae ${ }^{+}$cells and $\mathrm{CD}^{+} \mathrm{T}$ lymphocytes $(r=0.42 ; P<0.01)$. The number of $\mathrm{C}$. pneumoniae $^{+}$cells correlated with $C D 20^{+} B$ cells $(r=0.48 ; P<0.01)$.

Conclusion - M. pneumoniae and C. pneumoniae are more frequently found in TRP correlate with the intensity of the inflammation and diameter of the vessel (positive remodeling).

Keywords: Mycoplasma pneumoniae, Chlamydia pneumoniae, acute myocardial infarction

Instituto do Coração (InCor) of the Hospital das Clínicas of the FMUSP. Mailing address: Maria de Lourdes Higuchi - Rua Capote Valente, 361/142 05409-001 - São Paulo, SP, Brazil - E-mail: anplourdes@incor.usp.br English version by Stela Maris C. e Gandour
Inflammation of atherosclerotic plaque is an important factor of instability. However, the cause of this inflammation still remains unclear ${ }^{1,2}$. Oxidized low-density lipoproteins $(\mathrm{LDL})^{3,4}$, tissue factor ${ }^{5}$, and other factors have been considered important in the development of rupture and thrombosis of the plaque ${ }^{6,7}$. Infectious agents have been investigated and the results have been controversial. When infectious agents are found, sometimes their presence does not correlate with the degree of inflammation or stenosis, among other parameters. Therefore, doubt exists about whether the infectious agents play an active role in atherogenesis and in triggering of inflammation and plaque rupture or whether they are passive inhabitants of the plaque ${ }^{8-10}$. The low positivity or absence of infectious agents, mainly of Chlamydia pneumoniae (C. pneumoniae), and the presence of the antigen or heat shock protein of chlamydia has led authors to suggest indirect mechanisms of immunologic activation induced by those agents ${ }^{11,12}$. Most anatomicopathological studies have sought an association between $C$. pneumoniae and atherosclerotic plaques in general or the intensity of plaque obstruction ${ }^{13-15}$. Thrombosed ruptured plaques associated with myocardial infarction have not been analyzed, despite the clinical and serological evidence favoring the pathogenetic participation of $C$. pneumoniae in acute myocardial infarction. Studies ${ }^{16,17}$ attempting to correlate the levels of antibodies against $C$. pneumoniae or the presence of this bacterium in the circulating blood found no significant difference between patients experiencing or not experiencing acute myocardial infarction. However, clinical studies comparing patients treated with antibiotics versus those not treated after an episode of myocardial infarction showed that those treated with antibiotics evolved with fewer complications ${ }^{18,19}$, but this result was not maintained in a long-term follow-up ${ }^{20}$.

In a previous study ${ }^{21}$ using the techniques of immunohistochemistry, in situ hybridization (ISH), and electron microscopy, we reported a great amount of $C$. pneumoniae 
bacteria in the intra- and extracellular space of atherosclerotic plaques, in the media layer, and mainly in the adventitia of segments of unstable coronary arteries. However, $C$. pneumoniae was also identified in segments of coronary arteries with stable plaques without atherosclerosis, mainly in the adventitia, suggesting that $C$. pneumoniae is a common infectious agent of the adventitia of vessels, and that its increased proliferation leads to inflammation of the vascular wall and may contribute to vessel remodeling.

In a sequence of the reported studies ${ }^{22}$, we observed that, in addition to $C$. pneumoniae, another bacterium is found in unstable atherosclerotic plaques: Mycoplasma pneumoniae (M. pneumoniae).

Mycoplasmas are the smallest autoreplicating microorganisms known and they have unique characteristics, such as the absence of an outer wall and the need for cholesterol for survival ${ }^{23}$. Another important characteristic is that they induce alterations in the immunologic system of the host and, therefore, may favor the proliferation of other infectious agents. In the present study, we hypothesized that a close association between $M$. pneumoniae and $C$. pneumoniae may be related to the development of unstable atherosclerotic plaques and to the inflammation of the vessel as a whole.

The objective of the present study was, therefore, to assess the hypothesis that M. pneumoniae and C. pneumoniae are present in greater amounts in thrombosed ruptured plaques that cause fatal acute myocardial infarction and are associated with vessel inflammation.

\section{Methods}

The major coronary branches of the hearts obtained at autopsies were dissected, transversely sectioned at 3-mm intervals, and submitted to processing for paraffin embedding and histological analysis. The following segments of the coronary arteries (SCA) were selected for analysis:

Group A (unstable thrombosed plaque)-23 SCA of 23 patients who died due to acute myocardial infarction (AMI) with the thrombosed segment of the ruptured plaque responsible for AMI (10 females and 13 males; mean age of $65+7$ years $)$.

Group B (stable plaques of the same patients in group A) - 23 SCA containing stable plaques with a degree of obstruction similar to that of the thrombosed ruptured segment, but in another coronary artery branch.

Group C (nonruptured plaque with severe atherosclerosis in patients without AMI) - 11 SCA containing nonruptured plaques with obstruction greater than $70 \%$, responsible for clinical findings of chronic ischemia, in 11 patients who had undergone revascularization surgery and died due to causes other than AMI (11 males; mean age of $57+10$ years).

Group D (SCA of patients with no atherosclerosis) 11 SCA of 11 patients without atherosclerosis (patients with Chagas' disease or with idiopathic dilated cardiomyopathy) who died with no ischemic heart disease ( 3 females; 8 males; mean age of $44+13$ years).
The material of groups A and B corresponded to serial sections of the same segments analyzed in a previous study in regard to the constitution of the plaques and characterization of the cell subtypes of inflammation ${ }^{24,25}$, collected on autopsies performed from 1985 to 1986, when angioplasty and thrombolytic agents, which may change the morphology of the plaque and the diameter of the vessel, were not routinely used.

From each transverse section of the coronary artery selected, serial sections were taken in the search for Mycoplasma pneumoniae (M. pneumoniae) and Chlamydia pneumoniae (C. pneumoniae). The search for M. pneumoniae was performed through the detection of DNA by the in situ hybridization technique; the search for C. pneumoniae was performed through the detection of antigens in its external membrane with the immunoperoxidase technique. To confirm the findings of in situ hybridization and immunohistochemistry, autopsy material was prospectively collected for electron microscopy analysis from 5 more patients, who had recently died due to acute myocardial infarction. These segments were also studied with immunohistochemistry and in situ hybridization for M. pneumoniae and $C$. pneumoniae, but as the results did not differ, they were not included in the groups. Of these cases, 5 thrombosed ruptured SCA and 5 stable SCA were analyzed.

Histological 5- $\mu \mathrm{m}$ sections of the paraffin tissue blocks containing the SCA were submitted to antigen retrieval by heating (microwave) and incubated with the pure monoclonal antibody against $C$. pneumoniae (RR-402 clone, Dako, Carpinteria, CA, USA, antiprotein of the external membrane of $C$. pneumoniae). That antibody does not cross-react with adenovirus, respiratory syncytial virus, influenza virus types A and B, Chlamydia trachomatis, and with some serotypes of Chlamydia psittaci. The specificity of that antibody was checked in histological sections previously known to be positive for cytomegalovirus and herpes virus. The secondary antibody was antiimmunoglobulin of mouse produced in rabbit conjugated with biotin (Dako, Carpinteria, CA, USA) at a dilution of 1:200. Streptoavidin was then used conjugated with peroxidase (Amersham International, England) at a dilution of 1:100. The glass slides were kept in a solution of 3,3' diaminobenzidine (Sigma Chemical Corporation, St. Louis, MO, USA) and 6\% hydrogen peroxide for 10 minutes, being then counterstained with Harris' hematoxylin.

Five- $\mu \mathrm{m}$ thick sections of SCA embedded in paraffin were placed on glass slides covered with silane, were deparaffinized in xylol, and dehydrated in ethanol.

Cell permeability was provided with a $0.01 \mathrm{M}$ solution of citrate buffer $\mathrm{pH} 6.0+0.1$ in a microwave oven by using the same immunohistochemical protocol for antigen retrieval described above. The endogenous peroxidase was blocked with $3 \% \mathrm{H}_{2} \mathrm{O}_{2}$, and the free proteins in the tissue were blocked with serum blocker (DAKO Corporation, Carpinteria, CA, USA). Then, $20 \mu$ l of the following hybridization mixture were added to the sections: $10 \mu \mathrm{L}$ of the probe in deionized formamide, $50 \%$ of dextran sulfate, 20X SSC, Denhardt 
solution, DNA of salmon sperm, tRNA of yeast, poly A and poly $\mathrm{C}$, and water with diethylpirocarbonate. The probe of Mycoplasma pneumoniae was prepared from a highly specific clone of M. pneumoniae (Diagnósticos de Enzo, Farmingdale, NY, USA). The double strands of the target DNA and of the probe were denatured at $95+5^{\circ} \mathrm{C}$ for 6 minutes. DNA hybridization was performed for 18 hours. The nonspecific hybrids were removed by washings with $0.2 X$ SSC. The signal was amplified with the DAKO amplification system (CSA) (Carpinteria, CA, USA). Development was carried out with 3'3 diaminobenzidine (DAKO Corporation, Carpinteria, CA, USA), and the sections were counterstained with Harris' hematoxylin.

Double marking was performed in serial sections of the SCA of 2 cases in groups A and B, using the immunohistochemical technique with alkaline phosphatase (Amersham International, England) to mark C. pneumoniae (previously described protocol) and the ISH technique to mark $M$. pneumoniae.

Negative controls were obtained omitting the probe or the primary antibody. As a positive control for all reactions, sections of human tissue known to be positive for Mycoplasma pneumoniae or Chlamydia pneumoniae were used. As a positive control for the in situ hybridization technique, a probe of repeated sequence (alu1/alu2) of the Genetic Research (AL, USA) was used, and, as a negative control, a plasmid DNA marked with biotin (DAKO Corporation, Carpinteria, CA, USA) was used.

Study of the percentage of the area occupied by the $M$. pneumoniae DNA was performed with the image analysis system (Quantimet 500-Leica) assessing all the fields of the intima layer in a 20x objective. In regard to the number of positive cells for C. pneumoniae in the adventitia, the number of cells present in the first 400x field of the adventitia was counted beginning those in the external elastic membrane and surrounding the entire vessel. In the plaque, all intima fields were counted. The result was expressed as a mean number of positive cells per 400x field.

The data obtained regarding the percentage of the area of $M$. pneumoniae DNA in groups A and B were correlated with the amount of $C$. pneumoniae, with the number of $\mathrm{T}$ lymphocytes (CD4+ and CD8+) and B lymphocytes (CD20+) per 400x field, and with the percentage of the fatty area in the plaque ${ }^{23}$. In this study, the number of lymphocytes present in the width of the adventitia adjacent to the external elastic membrane surrounding a transverse section of the vessel in a $400 x$ field was counted. The mean number of lymphocytes per field was calculated and divided by $0.36 \mathrm{~mm}^{2}$ (area of the microscopic field), providing the mean number of lymphocytes per $\mathrm{mm}^{2}$. In the plaque, all lymphocytes were counted and divided by the area of the plaque in $\mathrm{mm}^{2}$.

In comparative analysis between 2 results in the same individual, the Wilcoxon test (non-normal distribution) was used to check the existence of a difference in the amount of $M$. pneumoniae DNA between groups A and B, and also the number of positive cells for $C$. pneumoniae. In the analysis of variance between different individuals, ie, between groups B,
C, and D, the Kruskal-Wallis test was used. Spearman rank correlation was used to assess possible correlations between the amount of bacteria and the amount of fat in the plaque, the area of the vessel, and the number of lymphocytes, because they did not have a normal distribution.

In the additional recent 5 cases submitted to electron microscopy, segments of coronary artery with ruptured plaque and segments with stable obstructive plaque were selected for study.

Transverse $0.3 \mathrm{~cm}$-thick sections of the selected segments were analyzed with a magnifying glass, and the material representing the thickest part of the plaque with its corresponding media layer and adventitia was collected. Fragments less than 1-mm thick were fixed in 3\% glutaraldehyde and $0.1 \mathrm{M}$ sodium phosphate buffer and postfixed in $1 \%$ osmium tetroxide. Then the fragments were washed in $0.9 \%$ saline solution and contrasted with uranyl acetate. Dehydration was performed with ethanol and propylene oxide. The fragments were emblocked in "araldite" resin, and ultrathin sections ( 60 to $90 \mathrm{~nm}$ ) were obtained and contrasted with a solution of $5 \%$ lead nitrate ${ }^{26}$.

\section{Results}

On electron microscopy, thrombosed ruptured plaques showed a great number of electron dense bodies compatible with $C$. pneumoniae both inside xanthomatous cells and in monocytes present in the lumen of the small vessels of the adventitia (vasa vasorum). Small round structures containing DNA- or RNA-type granules surrounded by a single membrane were adhered to the surface of endothelial cells, mainly of vasa vasorum (fig. 1A), their morphology being compatible with that of mycoplasmas; sometimes they seemed internalized within the cytoplasm (fig. 1B). Elementary bodies of $C$. pneumoniae (characterized by the presence of a double membrane surrounding the electron dense material) and small and round forms of mycoplasmas in the extracellular matrix (fig. 1A, fig. 1C, and fig. 1D) were frequently found side by side inside the endothelium and in the subendothelial space. Macrophages of the adventitia and monocytes of the blood were also coinfected by these 2 bacteria (fig. 1E and fig. 1F).

Examination of the lipid core showed a great quantity of fragmented or collapsed membranous structures beside ellipsoid or round forms of granular material surrounded by a membrane measuring from 0.1 to $0.4 \mathrm{~mm}$ amidst the clear clefts of cholesterol crystals, which were interpreted as compatible with mycoplasmas (fig. 2A and fig. 2B). The examination with the in situ hybridization technique described below confirmed the diagnosis of mycoplasmas, which were identified as Mycoplasma pneumoniae.

In the adventitia of thrombosed ruptured plaques, macrophages containing many elementary bodies of $C$. pneumoniae were frequently found beside mycoplasmas in the extracellular space (fig. 2C and fig. 2D).

In the stable plaque, the forms of $C$. pneumoniae were rare, while mycoplasmas, in their round or cylindrical forms, 

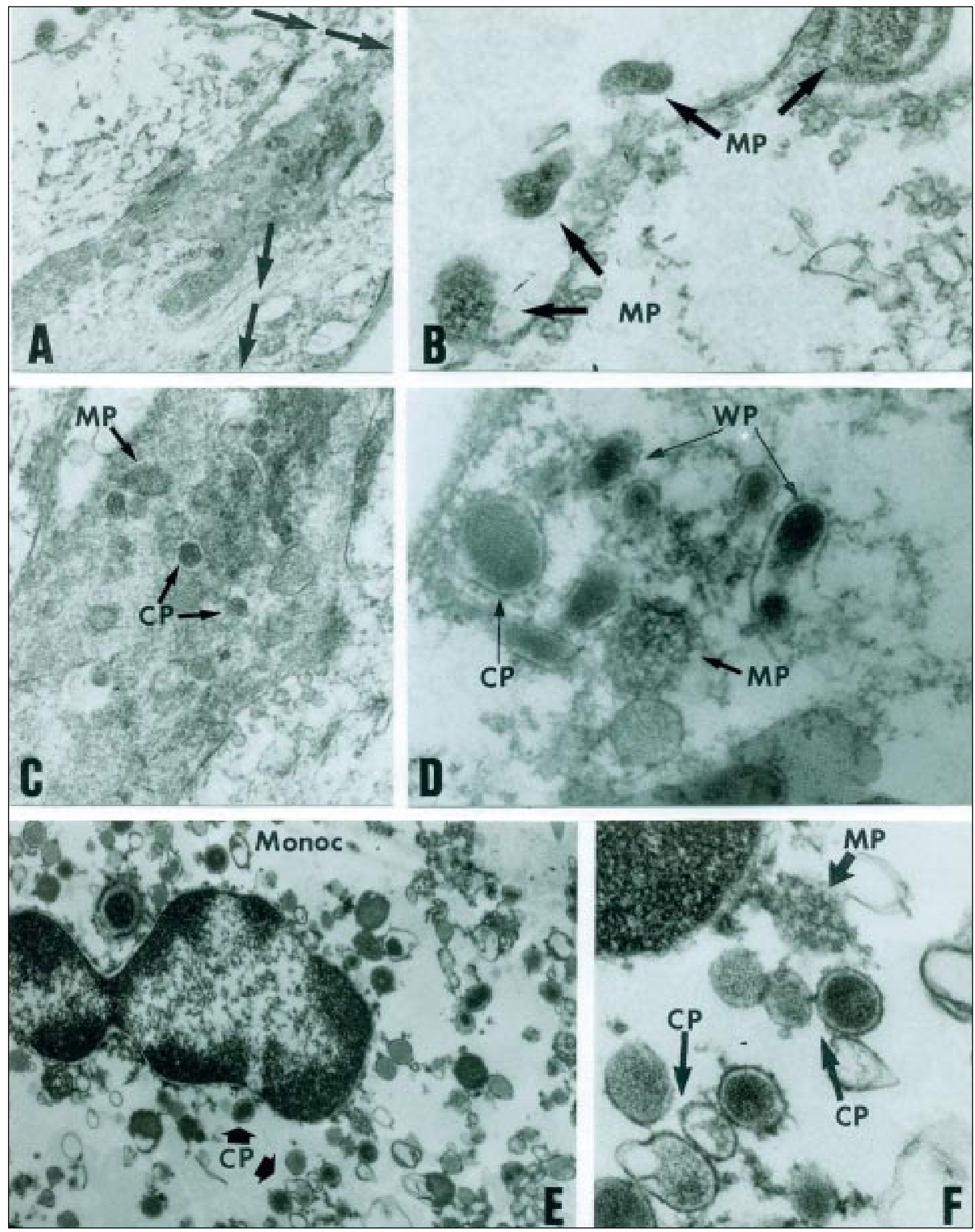

Fig. 1 - Ultrastructural characteristics of $M$. pneumoniae (MP) and its association with $C$. pneumoniae $(\mathrm{CP})$ in segments of coronary arteries with ruptured and thrombosed plaques: A) panoramic view of vasa vasorum showing mycoplasmas adhered to and being internalized in the endothelial cell. In the subendothelial space, both bacteria $M$. pneumoniae (MP) and C. pneumoniae (CP) can be seen in the extracellular space (2.600X - originals). The arrows indicate that these regions are magnified in the following figures; B) a great magnification of A, showing in detail the surface of the endothelial cell with $M$. pneumoniae adhered (arrows), one of which internalized in the endothelial cell (7200X); C) great magnification of A, exhibiting in detail 2 types of extracellular bacteria M. pneumoniae (elliptic form with granules) and C. pneumoniae (electron dense round form) in the subendothelial space (7200X); D) great magnification of an endothelial cell [identified by the presence of Weibel-Palade bodies (WP)] coinfected with M. pneumoniae and $C$. pneumoniae (10,000X); E) circulating monocytes with numerous bacteria in their cytoplasm with characteristics of $C$. pneumoniae and M. pneumoniae, which are better shown in the following magnification $(3330 \mathrm{X}) ; \mathrm{F})$ greater magnification of E showing in detail the elementary bodies of $C$. pneumoniae and the round forms of M. pneumoniae (10,000X) 
were more frequent. In the adventitia of the segments containing these stable plaques, forms compatible with large mycoplasmas were detected and characterized by electron dense granules and filaments (fig. 2E), a surrounding membrane, and lack of organelles. These mycoplasmas had in their extremities a more electron-dense region resembling the
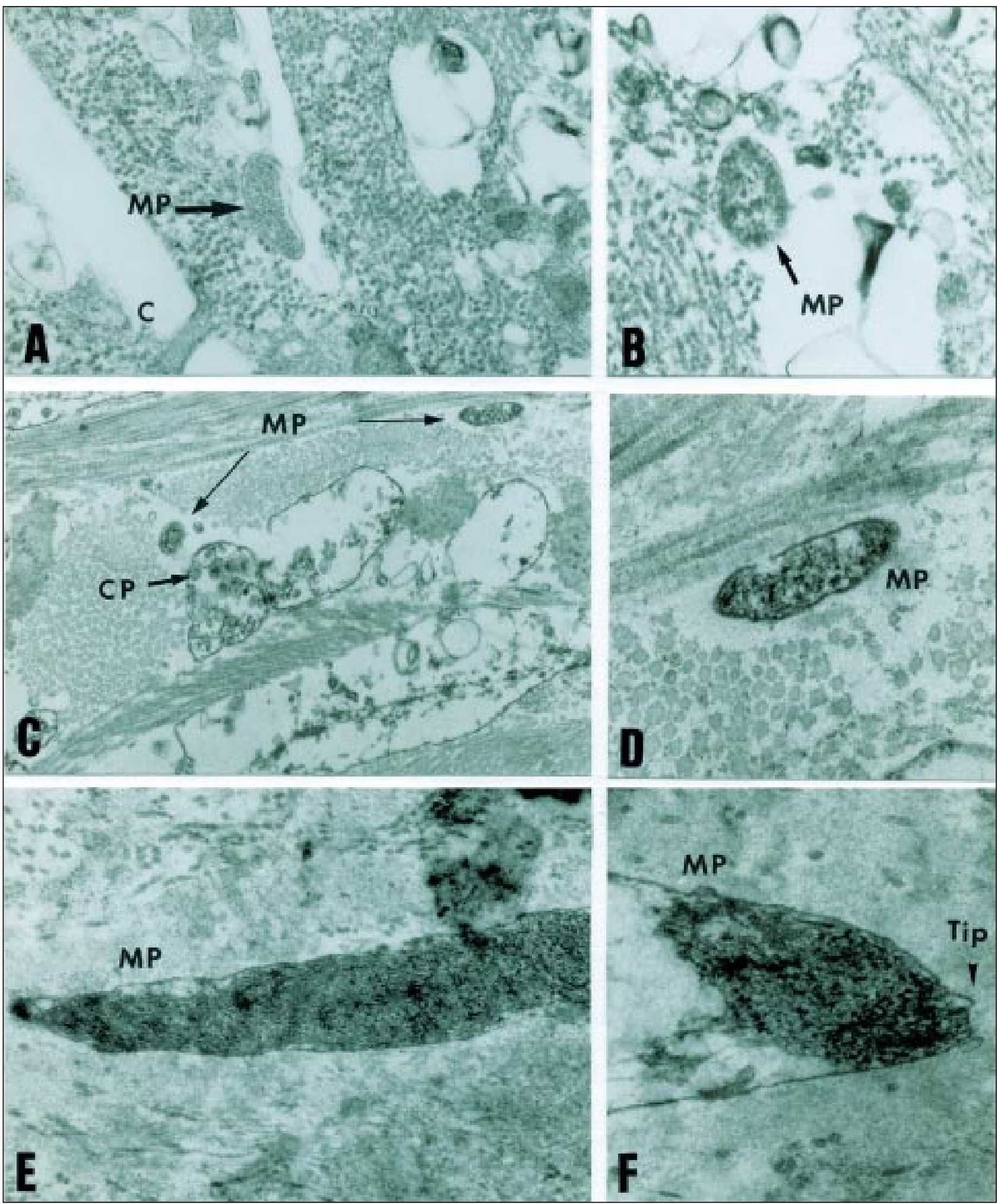

Fig. 2 - Ultrastructural characteristics of the ruptured plaque (A-D) and of the stable plaque (E-F) of a coronary artery: A and B) lipid core of the atheroma showing many membranous remnants, cholesterol crystals (c) in clefts, and small cylindrical forms of $M$. pneumoniae (MP), 7,200X and 10,000X, respectively; C) segment with ruptured plaque showing, in the adventitia, a macrophage containing many small forms of C. pneumoniae (CP arrow) in the cytoplasm, and, in the extracellular space, round or cylindrical forms of M. pneumoniae (MP arrows) 3,300X;D) detail of C, showing M. pneumoniae (MP) with a surrounding membrane and material of the DNA type inside (10,000X); E) a large cylindrical form of $M$. pneumoniae (MP) in the adventitia of a stable plaque; F) detail of the more electron dense extremity of M. pneumoniae (MP) suggestive of an adhesion organelle ("tip") (10,000X). 
so-called "tip" - the adhesion organelle of the mycoplasma to the host cell (fig. 2F).

The counting of the mean number of cells positive for the $C$. pneumoniae antigen per 400x field in the plaque was as follows in groups A, B, C, and D, respectively: $3.3 \pm 3.6$; $1.0 \pm 1.3 ; 1.2 \pm 2.4 ;$ and $0.4 \pm 0.3$. That counting in the adventitia was as follows in groups A, B, C, and D, respectively: $10.7 \pm 11.2 ; 4.9 \pm 5.1 ; 5.2 \pm 5.2$; and $2.0 \pm 1.7$. The positivity of the reaction was mainly present in the cytoplasm of macrophages, fibroblasts of the adventitia, smooth muscle fibers of the outer portion of the media layer, plasma cells, endothelial cells, and in the extracellular matrix.

In situ hybridization (ISH) for C. pneumoniae showed the corresponding DNA in macrophages of the plaque, smooth muscle cells of the media layer, and fibroblasts and macrophages of the adventitia, in addition to numerous extracellular positive granules.

The ISH technique for the M. pneumoniae DNA revealed, in group A, a great quantity of extracellular positive granules (brown), mainly in the fatty areas of the plaques (fig. 3A). The cytoplasm of xanthomatous cells also showed intense positivity (fig. 3B). The preparations with double marking revealed that the xanthomatous cells present in the ruptured plaques were coinfected with M. pneumoniae and C. pneumoniae (fig. 3C). Low positivity for M. pneumoniae was also detected in the media layer and adventitia of the segments with thrombosed ruptured plaques in the extraand intracellular spaces (fig. 3D).

In the segments with stable plaques (groups B and C), the amount of positive points for M. pneumoniae DNA was, in general, much smaller (fig. 3E) both in the plaque and in the media layer and adventitia.

In group D (nonatherosclerotic patients), practically no $M$. pneumoniae DNA existed in the region of the intima layer (fig. 3F), but rare positive foci were identified in the adventitia in some cases.

The percentage of the area of M. pneumoniae DNA and the mean number of positive cells for $C$. pneumoniae inside the plaques in groups $\mathrm{A}, \mathrm{B}, \mathrm{C}$, and $\mathrm{D}$, and the transverse area of the vessel and the mean number of lymphocytes $/ \mathrm{mm}^{2}$ in the plaque of groups A and B were compared and are shown in table I.

Comparing the quantity of C. pneumoniae in groups $\mathrm{A}$ and $\mathrm{B}$ with the Wilcoxon test (comparison in a single individual), a greater amount was found in group $A$ both in the plaque $(\mathrm{P}=0.001)$ and in the adventitia $(\mathrm{P}=0.001)$, and, in group A, the quantity of $C$. pneumoniae was greater in the plaque than in the adventitia. The comparison of the amount of C. pneumoniae in groups $\mathrm{B}, \mathrm{C}$, and $\mathrm{D}$ showed that group $B$ had values statistically greater than those in group $D$ $(\mathrm{P}=0.04)$ in the adventitia, but no difference was observed in the plaques $(\mathrm{P}=0.79)$.

The percentages of plaque area occupied by M. pneumoniae DNA were significantly higher in group A than those in group $\mathrm{B}(\mathrm{P}<0.01$ - Wilcoxon test $)$. Comparing the 3 independent groups $\mathrm{B}, \mathrm{C}$, and $\mathrm{D}$, no difference was observed between groups $\mathrm{B}$ and $\mathrm{C}(\mathrm{P}=0.3)$; however, a greater quantity was observed in group $B$ as compared with that in group $\mathrm{D}(\mathrm{P}=0.03)$, and a nonsignificant difference was observed between groups $\mathrm{C}$ and $\mathrm{D}(\mathrm{P}=0.06)$.

As no difference was observed between groups $\mathrm{B}$ (stable plaques in infarcted patients) and C (stable plaques in patients who did not die from infarction), the group $\mathrm{B}$ values were considered as representative of stable plaques in general. Data for groups A and B were grouped for the correlation test between the quantity of infectious agents and the characteristics of the vessel in regard to vascular remodeling and inflammation.

Significant positive correlations were found as follows: between the percentage of the area occupied by the M. pneumoniae DNA in the plaque and the area of the vessel $(\mathrm{r}=0.46$ and $\mathrm{P}=0.001$; fig. $4 \mathrm{~A})$; between the number of positive cells for $C$. pneumoniae in the adventitia and the number of $\mathrm{B}$ cells $/ 400 \mathrm{x}$ field in the adventitia $(\mathrm{r}=0.48$ and $\mathrm{P}<0.001-$ fig. $4 \mathrm{~B})$ and the number of $\mathrm{CD} 8^{+} \mathrm{T}$ cells $(\mathrm{r}=0.33$ and $\mathrm{P}=0.02)$, but not $\mathrm{CD} 4^{+} \mathrm{T}$ cells $(\mathrm{r}=0.10$ and $\mathrm{P}=0.50)$. No correlation was found between the quantity of M. pneumoniae DNA in the plaque and the following: number of positive cells for $C$. pneumoniae $(\mathrm{r}=0.06)$, mean number of $\mathrm{CD} 4^{+}$ Tlymphocytes $(\mathrm{r}=0.12)$ and $\mathrm{CD} 8^{+} \mathrm{T}$ lymphocytes $(\mathrm{r}=-0.07)$ or CD20+ B lymphocytes per 400x field. A good correlation was found between the quantity of C. pneumoniae in the plaque and the mean number of $\mathrm{CD}^{+} \mathrm{T}$ cells $(\mathrm{r}=0.48$ and $\mathrm{P}<0.01$ ) and $\mathrm{CD}^{+}$T cells $(\mathrm{r}=0.31$ and $\mathrm{P}=0.04)$, but not $\mathrm{CD} 20^{+}$ $\mathrm{B}$ cells. Intracellular coinfection with $C$. pneumoniae and $M$. pneumoniae was found in a great quantity of xanthomatous macrophages mainly, but not exclusively, present in ruptured plaques.

\section{Discussion}

The current vision of the pathogenesis of atherosclerosis comprises elements of old theories and modern concepts and defines atherosclerosis as a response to the endothelial injury of the arteries associated with endothelial dysfunction ${ }^{27-29}$. Under such conditions, the following occurs: an increase in vascular permeability for the components of the plasma, mainly lipids, and an accumulation of monocytes and platelets in the endothelium and subendothelial space. When repeated and chronic, this injury leads to the development of the atherosclerotic plaque.

One important contribution for elucidating the pathogenesis of atherosclerosis is the observation that large particles of LDL can cross the endothelial barrier and carry cholesterol from the circulating blood to the interior of the arterial intima ${ }^{30-32}$. With the entrance of lipids in the plaque, the following occur: stimuli for cell proliferation ${ }^{33}$, induction of production of cytokines ${ }^{34}$, and, consequently, inflammation ${ }^{35}$. The following question arises: Why does LDL in animals fed a cholesterol-rich diet or LDL in hypercholesterolemic people stimulate the proliferation of arterial cells?

The present study compared 4 groups of segments of coronary arteries and observed that M. pneumoniae was present in the intima layer of almost all segments of the 

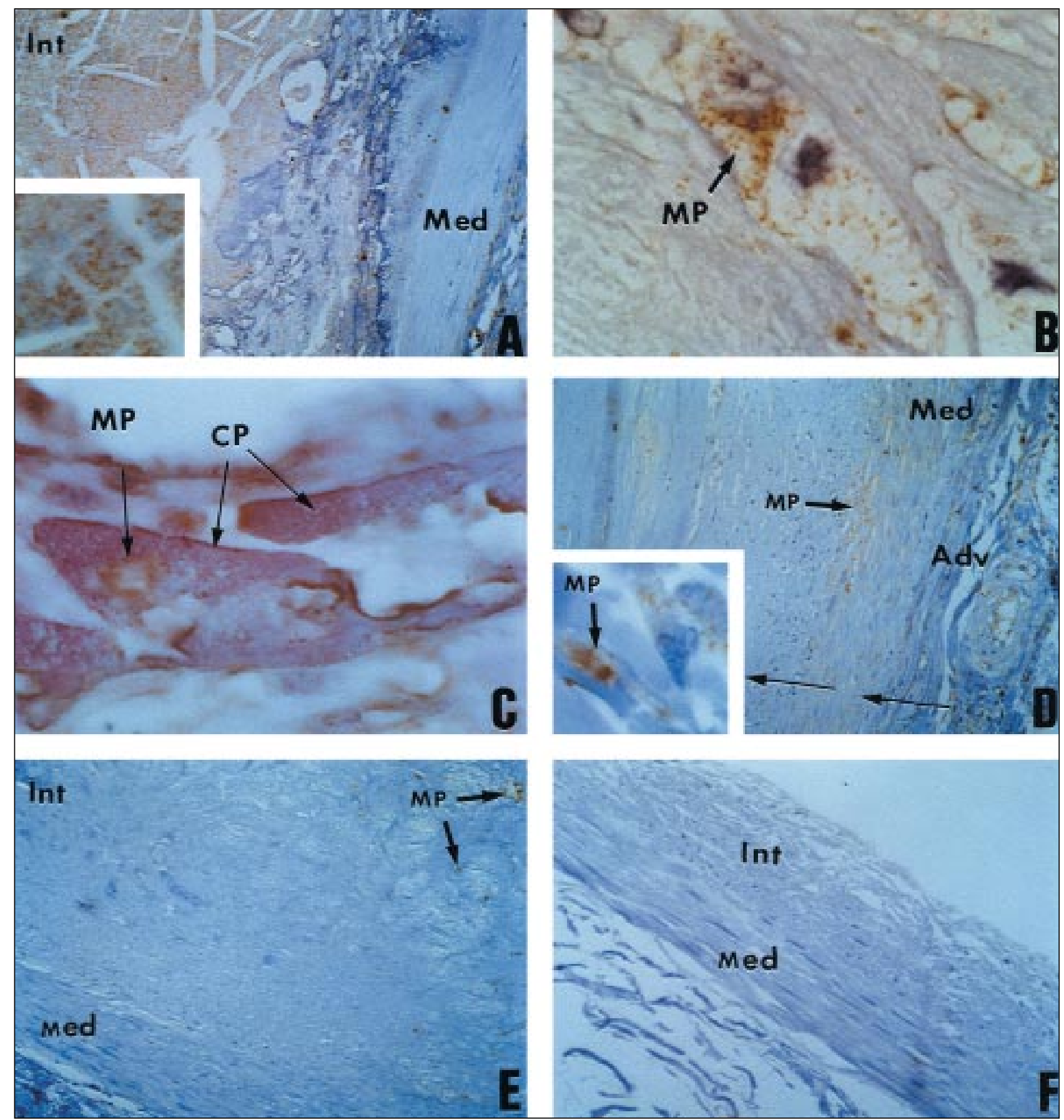

Fig. 3 - Photomicrographies of the histological sections of coronary arteries with unstable (A-D) and stable (E) plaques, and a nonatherosclerotic segment (F) submitted to in situ hybridization with a probe for the M. pneumoniae DNA, showing brown positive granules: A) atheroma with a large amount of fatty material and numerous positive granules of M. pneumoniae (100X) seen in detail in a larger magnification (1,000X); B) xanthomatous cell containing numerous positive granules of $M$. pneumoniae amidst clear fatty vacuoles $(1,000 \mathrm{X})$; C) double marking - through immunohistochemistry, anti-C. pneumoniae is revealed with alkaline phosphatase (pink), and, with the in situ hybridization technique (brown), the probe for the M. pneumoniae DNA is evident, showing the coinfection of xanthomatous macrophages (1,000X); D) media layer and adventitia of the segment with a ruptured plaque showing the great amount of $M$. pneumoniae in the media layer and in the adventitia (160X). In detail, the great magnification shows larger forms of M. pneumoniae in the extracellular matrix of adventitia (1,000X); E) segment with a stable plaque showing the smaller amount of $M$. pneumoniae in the atheroma (100X); F) absence of $M$. pneumoniae in a nonatherosclerotic case-control (100X).

vessels studied, but in a greater quantity in the fatty areas of the atheromas. Therefore, they were present in greater amounts in ruptured plaques, which may be attributed to the fact that the vulnerable plaques are softer and contain a greater quantity of cholesterol, because the mycoplasmas only proliferate in cholesterol-rich media. Confirming pre- vious findings ${ }^{21}$, the ruptured plaques also had elevated quantities of $C$. pneumoniae, which were present not only in the plaque, but also, and in higher numbers, in the adventitia. C. pneumoniae was present in the adventitia of almost all samples studied, independent of the presence of atherosclerosis. However, it was found in greater amounts in the 
Table I - Amount of M. pneumoniae and C. pneumoniae, percentage of the fatty area, mean number of B lymphocytes (CD20+) and subtypes of $\mathrm{T}$ lymphocytes $(\mathrm{CD} 4+$ and $\mathrm{CD8}+) / \mathrm{mm}^{2}$ in the plaques of groups $\mathrm{A}, \mathrm{B}, \mathrm{C}$, and D

\begin{tabular}{|c|c|c|c|c|c|c|}
\hline Group & N. C. pneumoniae $1400 \mathrm{x}$ & $\%$ M. pneumoniae area & $\%$ Fatty area & CD20+ & $\mathrm{CD} 4+$ & CD8+ \\
\hline A & $3.3( \pm 3.6)$ & $3.9( \pm 3.5)$ & $33.7( \pm 22.3)$ & $5.9( \pm 19.6)$ & $7.4( \pm 6.6)$ & $13.8( \pm 25.4)$ \\
\hline $\mathrm{B}$ & $1.0( \pm 1.3)$ & $1.5 \pm 1.6)$ & $6.8( \pm 11.6)$ & $1.1( \pm 1.6)$ & $3.4( \pm 4.0)$ & $5.7( \pm 6.3)$ \\
\hline $\mathrm{C}$ & $1.2( \pm 2.4)$ & $0.9( \pm 0.9)$ & np & np & np & np \\
\hline $\mathrm{D}$ & $0.4( \pm 0.3)$ & $0.3( \pm 0.2)$ & $\mathrm{np}$ & $\mathrm{np}$ & $\mathrm{np}$ & $\mathrm{np}$ \\
\hline
\end{tabular}

np: not performed; N. C. pneumoniae/400x: mean number of Chlamydia pneumoniae per 400x field;\% M. pneumoniae area: percentage of the area occupied by Mycoplasma pneumoniae.

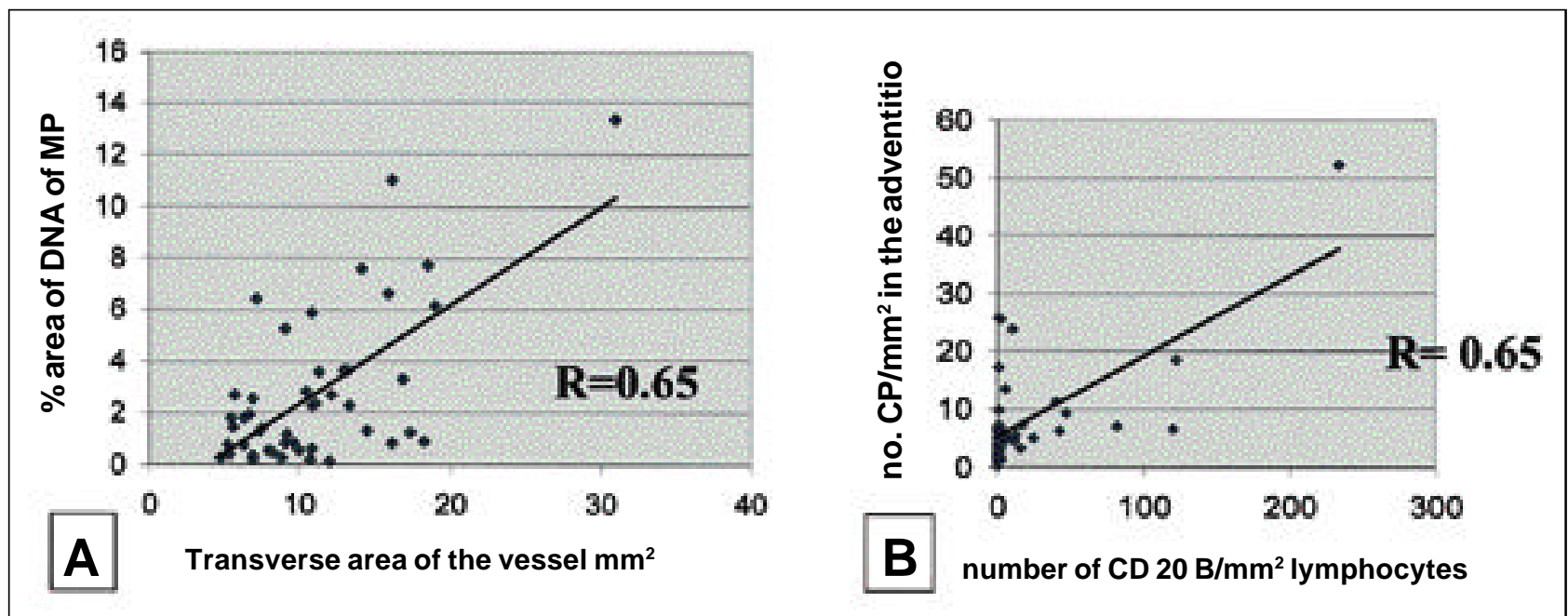

Fig. 4 - Positive correlations between the morphologic characteristics of vulnerability of the atherosclerotic plaque and the amount of bacteria. Fig. $4 \mathrm{~A}$ - Positive correlation between the transverse area of the vessel (positive remodeling) and the amount of Mycoplasma pneumoniae (MP) DNA. Fig. 4B - Positive correlation between the number of cells positive for Chlamydia pneumoniae (CP) and the number of CD20 B lymphocytes in the adventitia.

ruptured segments. Practically no study reporting an association between mycoplasmas and atherosclerosis exists in the literature. Experimental studies about the infection of rabbits with mycoplasmas could not show a pathogenetic role played by that bacterium in the development of atherosclerosis ${ }^{36}$. Our team, studying ultrastructurally and with immunohistochemistry the lungs of apparently healthy laboratory animals (rats and mice), observed that $100 \%$ of the animals were infected with Mycoplasma pulmonis and C. pneumoniae ${ }^{37}$, leading us to believe that laboratory animals may often be naturally infected with these bacteria. This requires further study, because that infection may potentially influence the results of experimental research on atherosclerosis.

On electron microscopy, we could document mycoplasmas in the endothelial intercellular space or being internalized by the endothelial cells of ruptured plaques. The close association of mycoplasmas and chlamydiae may favor the proliferation of both bacteria. In the present study, these 2 bacteria were present in great quantities in the thrombosed ruptured plaques, and, sometimes in contact with each other, both in the extracellular space and inside endothelial cells and macrophages. This finding was mainly based on electron microscopy and was confirmed in the cases in which double marking was performed. The presence of these bacteria inside ruptured plaques may explain previously known characteristics of these plaques as follows: oxidized LDL, an increase in the production of several cytokines, an increase in TNF, cell proliferation, and inflammation.

Mycoplasmas have been held responsible for human diseases, such as pneumonia, arthritis, and urethritis ${ }^{38}$. More recently, they have also been implicated in the progression of AIDS, chronic fatigue syndrome, acute respiratory distress syndrome, and others ${ }^{39}$. However, these arguments have not succeeded in sensitizing scientists in regard to a pathogenetic relation, because most of these arguments are based on case reports whose positivity for mycoplasmas results from serological data, culture, or PCR ${ }^{40,41}$. Few studies sought $M$. pneumoniae in atherosclerotic plaques, and the results were negative ${ }^{42}$ or slightly positive ${ }^{43}$. The difference in the results here presented may have originated in the methodology used. We did not use PCR but in situ hybridization with a very specific probe and a system of amplification to reveal the reaction (CSA), and electron microscopy.

In the present study, M. pneumoniae and C.pneumoniae were very frequently shown in atherosclerotic plaques. Quantitative analysis was not performed with all techniques used, because the qualitative analysis confirmed the presence of these agents with the 3 techniques used in the same locations and in the same cells. 
In situ hybridization and an image analysis system for the detection of the fraction of the area occupied by mycoplasma DNA were used. Chlamydiae were quantified in the immunohistochemical glass slides, because, as they are predominantly intracellular, the homogeneous color of the positive cytoplasm enabled counting the number of positive cells.

The electron microscopy showed structures delimited by a single membrane and containing a granular material in its interior, compatible with the morphology of mycoplasmas. The most densely positive sites for M. pneumoniae were those rich in fat, which are adequate for the proliferation of mycoplasmas.

The lack of characteristic morphology and cell wall may have made the identification of these agents on electron microscopy difficult, because they may have been misinterpreted as irregular cell prolongations.

Vulnerable plaques are rich in lipids and in xanthomatous cells ${ }^{44}$, mainly of the oxidized LDL type ${ }^{45,46}$, which play a major role in the development of plaque inflammation, rupture, and thrombosis ${ }^{47}$. Monocytes and circulating neutrophils may contain $C$. pneumoniae ${ }^{48}$, independently of the association with atherosclerosis. However, an increased number of macrophages expressing myeloperoxidase has been seen in ruptured or eroded plaques and not in fatty streaks ${ }^{49}$. Our findings suggest that the xanthomatous macrophages of the atherosclerotic plaques are full of mycoplasmas and chlamydiae. We cannot state that this coinfection occurs only in the ruptured plaques, because the nonruptured plaques of groups B and C many times had characteristics of instability, such as many xanthomatous cells and inflammation.

Antioxidant agents may have a beneficial effect on the prevention of atherosclerotic complications ${ }^{50-52}$. Epitopes of oxidized LDL are sufficiently antigenic to produce an inflammatory reaction in the arterial wall, suggesting a possible autoimmune reaction ${ }^{53,54}$. One characteristic of the mycoplasmas is the induction of oxidation ${ }^{55}$ and formation of free radicals in the host cells and in the environment ${ }^{56-58}$; antioxidation has a preventive effect against infection by mycoplasma ${ }^{59}$. When the cells are coinfected with a virus, an increase in the pathogenicity of both infectious agents occurs ${ }^{60,61}$. Mycoplasmas have anchoring lipoproteins on the external surface of their plasma membrane, which may be an explanation for why they are not recognized by the defense immune system of the host ${ }^{62}$.

Mycoplasmas are known to induce the host's inflammatory cells to produce cytokines, mainly IL1, IL-6, and IL2 , TNF- $\alpha$, and IFN $\gamma^{63,64}$. M. pneumoniae and others induce depression in the immune response ${ }^{65,66}$, mainly of T cells, through a possible mechanism of apoptosis ${ }^{67,68}$, with a reduction in the CD4 T cells ${ }^{69}$, which may be a facilitating mechanism for other infections. This possible action of mycoplasmas, increasing the virulence of other agents, has been studied in AIDS patients ${ }^{70}$. Increased levels of cytokines and a low number of CD4 T cells are characteristics also present in unstable plaques.
Another important point is that mycoplasmas have promitogenic activity ${ }^{71,72}$. On the other hand, a recent study ${ }^{73}$ has shown that chlamydial infection inhibits apoptosis in the host cell. Therefore, the presence of infection with chlamydia and mycoplasma may explain the proliferation of smooth muscle cells and the fact of their monoclonality ${ }^{74,75}$ in atherosclerotic plaques.

According to what has been said, we believe that the present study contributes with strong evidence favoring the theory that infectious agents are present in atherosclerotic plaques and participate actively in their genesis and instability. Therefore, we formulated the hypothesis that mycoplasmas seem to actively penetrate the endothelial cell (based on our observations on electron microscopy), causing its injury and dysfunction, favoring the entrance of fat to the subendothelial space. The proliferation of mycoplasmas may occur in this focal accumulation of fat, causing depression of the immunological system, contributing to the proliferation of chlamydiae (high levels of CD8+ T cells and low levels of CD4+ T cells and CD20+B cells were found in the plaques). The great proliferation of chlamydiae induces inflammation that contributes to weakening of the vascular wall and of the fibrosis cover, leading to rupture of the plaque (C. pneumoniae was present in greater numbers in the adventitia than in the plaque and showed a correlation with the number of $\mathrm{CD} 20+\mathrm{B}$ cells in the adventitia). The fact that chlamydiae are present in the vascular segments without atherosclerosis suggests that they are usual inhabitants with low pathogenicity.

The close association between $C$. pneumoniae and $M$. pneumoniae was seen on electron microscopy only in the ruptured plaques, mainly in xanthomatous cells. We believe that nonruptured plaques with a large number of xanthomatous macrophages, and, therefore, vulnerable ${ }^{2}$ may also have this coinfection. Despite this close association, no correlation was found between the number of cells positive for C. pneumoniae and the quantity of M. pneumoniae DNA. This result may be explained by the fact that antigens of one bacterium were compared with the DNA of another. The antigen may remain positive in the tissue longer than DNA may, after degradation of the bacterium. Studies aiming at comparing the same elements in the 2 bacteria are being carried out in our laboratory. In accordance with our theory, a correlation was found between the transverse area of the vessel and the percentage of the area of M. pneumoniae DNA in the plaque, suggesting a relation between the proliferation of mycoplasmas and the positive remodeling of the vessel.

Degeneration and death of these 2 bacteria may also explain the abundant membranous material amidst the lipid core observed in our and other authors' studies ${ }^{76}$. Round membranous structures with no electron dense content identified inside the plaque seem to derive from monocytes and apoptotic lymphocytes and have a procoagulant potential and activity of tissue factor ${ }^{77}$. The highly thrombogenic tissue factor present in ruptured plaques may correspond to remnants of mycoplasmas and chlamydiae.

Experimentally, inhalation of M. pneumoniae produ- 
ced no changes in atherosclerosis in rabbits, favoring our hypothesis that both bacteria are important for the development of those complications ${ }^{78}$.

In conclusion, our study strongly supports the hypothesis that atherosclerosis and plaque rupture are infectious complications of the artery and not simple degenerative processes. M. pneumoniae is present in almost all coronary atheroma. A large amount of M. pneumoniae and C. pneumoniae seems fundamental for the development of plaque instability, possibly in a symbiotic relation. The increase in the number of C. pneumoniae was correlated with an increase in the number of inflammatory cells, which, in turn, was greater in the segments with ruptured plaque. Our morphological findings favor the active participation of mycoplasmas in vulnerable plaques, by entering the subendothelial space and creating conditions that favor fat accumulation, dysfunction of the immunological and endothelial response, proliferation of chlamydiae, inflammation, and an increase in apoptosis, which are fundamental ingredients for plaque rupture.

\section{References}

1. van der Wal AC, Pieck JJ, de Boer OJ, et al. Recent activation of the plaque immune response in coronary lesions underlying acute coronary syndromes. Heart 1998;80:14-8

2. Libby $P$, Geng YJ, Aikawa M et al. Macrophages and atherosclerotic plaque instability. Curr Opin Lipidol 1996;7:330-5.

3. Yasunobu Y, Hayashi K, Shingu T, Yamagata T, Kajiyama G, Kambe M. Coronary atherosclerosis and oxidative stress as reflected by autoantibodies against oxidized low-density lipoprotein and oxysterols. Atherosclerosis 2001;155:445-53.

4. Gobel H, van der Wal AC, Teeling P, van der Loos CM, Becker AE. Metallothionein in human atherosclerotic lesions: a scavenger mechanism for reactive oxygen species in the plaque? Virchows Arch 2000;437:528-33.

5. Wilcox JN, Smith KM, Schwartz S, Gordon D. Localization of tissue factor in the normal vessel wall and in the atherosclerotic plaque. Proc Natl Acad Sci USA 1989;86:2839-43

6. Marmur JD, Thiruvikraman SV, Fyfe SV, et al. The identification of tissue factor in human coronary atheroma. Circulation 1996;94: 226-36.

7. Moreno PR, Bernardi VH, Lopez-Cuellar J, et al. Macrophages, smooth muscle cells and tissue factor in unstable angina: implications for cell mediated thrombogenicity in acute coronary syndromes.Circulation 1996;94:3090-7.

8. Mahony JB, Coombes BK. Chlamydia pneumoniae and atherosclerosis: does the evidence support a causal or contributory role? FEMS Microbiol Lett 2001;197:1-9.

9. Burian K, Kis Z, Virok D, et al. Independent and joint effects of antibodies to human heat-shock protein 60 and Chlamydia pneumoniae in the development of coronary atherosclerosis. Circulation 2001;103:1503-8

10. Vink A, Poppen M, Schoveveld AH, et al. Distribution of Chlamydia pneumoniae in the human arterial system and its relation to the local amount of atherosclerosis within the individual. Circulation 2001;103:1613-7.

11. Kol A, Sukhova GK, Lichtman AH, Libby P. Chlamydial heat schock protein 60 localizes in human atheroma and regulates macrophage tumor necrosis factoralpha and matrix metalloproteinase expression. Circulation 1998;98:300-7.

12. Kalayoglu MV, Indrawati, Morrison RP, Morrison SG, Yuan Y, Byrne GI. Chlamydial virulence determinants in atherogenesis: the role of chlamydial lipopolysaccharide and heat shock protein 60 in macrophage-lipoprotein interactions. J Infect Dis 2000; 181(Supp13): S483-9.

13. Thomas M, Wong Y, Ajaz M, Tsang V, Gallagher PJ, Ward ME. Relation between direct detection of Chlamydia pneumoniae DNA in human coronary arteries at postmortem examination and histological severity (Stary grading) of associated atherosclerotic plaque. Circulation 1999; 99: 2733-6.

14. Ericson K, Saldeen TG, Lindquist O, Pahlson C, Mehta JL. Relationship of C.pneumoniae infection to severity of human coronary atherosclerosis. Circulation 2000;101:2568-71.

15. Espinola-Klein C, Rupprecht HJ, Blanknenberg S, et al. Impact of infectious burden on extent and long-term prognosis of atherosclerosis. Circulation 2002;105:15-21.

16. Wald NJ, Law MR, Morris JK, Zhou X, Wong Y, Ward ME. Chlamydia pneumoniae infection and mortality from ischaemic heart disease: large prospective study. BMJ 2000;321:204-7.

17. Maass M, Jahn J, Gieffers J, Dalhoff K, Katus HA, Solbach W. Detection of Chlamydia pneumoniae within peripheral blood monocytes of patietns with unstable angina or myocardial infarction. J Infect Dis 2002;181(Suppl 3):S449-51.

18. GurfinkelE, Bozovich G, Beck E, et al. Treatment with antibiotic roxithromycin in patients with acute non-Q-waved coronary syndromes. The final report of the ROXIS Study. Eur Heart J 1999;20:121-7.
19. Neumann F, Kastrati A, Miethke T, et al. Treatment of Chlamydia pneumoniae infection with roxithromycin and effect on neointima proliferation after coronary stent placement (ISAR-3): a randomized, double-blind, placebo-controlled trial. Lancet 2001;357:2085-9.

20. WIZARD study, presented in 51st American College Cardiology Scientific Session, Atlanta 2002.

21. Higuchi ML, Castelli JB, Aiello VD, et al. Great amount of Chlamydia pneumoniae in ruptured plaque vessel segments at autopsy. A comparative study with stable plaques. Arq Bras Cardiol 2000;74:149-51.

22. Higuchi ML, Sambiase N, Palomino S, et al. Detection of Mycoplasma pneumoniae and Chlamydia pneumoniae in ruptured atherosclerotic plaques. Braz J Med Biol Res 2000;33:1023-6.

23. Razin S, Yogev D, Naot Y. Molecular Biology and pathogenicity of mycoplasmas. Microbiol Molec Biol Rev 1998;62:1094-156.

24. Bezerra HG, Higuchi ML, Gutierrez PS, et al. Atheromas that cause fatal thrombosis are usually larger and frequently accompanied by vessel enlargement. Cardiovasc Pathol 2001;10:189-96.

25. Higuchi ML, Gutierrez PS, Bezerra HG, et al. - Comparison between adventitia and intimal inflammation of ruptured and non-ruptured atherosclerotic plaques in human coronary arteries. Arq Bras Cardiol, 2002;79:20-24.

26. Reynolds ES. The use of lead citrate at high $\mathrm{pH}$ as an electron-opaque stain in electron microscope. J Cell Biol 1963;17:208-12.

27. Ross R. The pathogenesis of atherosclerosis: a perspective for the $1990 \mathrm{~s}$ Nature. 1993;362:801-8.

28. Fuster V,Badimon L, Badimon JJ, Chesebro JH. The pathogenesis of coronary artery disease and the acute coronary syndromes. N Engl J Med 1992;326:242-50.

29. Ross R - Atherosclerosis - an inflammatory disease. N Engl J Med 1999;340 115-26.

30. French JE. Endothelial structure and function. In: Jones RJ, ed. Evolution of the aterosclerotic plaque. Chicago, III: University of Chicago Press; 1963:15-33.

31. Kao V, Wissler RW. A study of the immunohistochemical localization of serum lipoproteins and other plasma proteins in human atherosclerotic lesions. Exp Mol Pathol 1965;4:465-79.

32. Zilversmith DB. Cholesterol flux in atherosclerotic plaque. Ann N Y Acad Sci. 1968;149:710-24.

33. Ross R. Atherosclerosis: a problem of the biology of arterial wall cells and their interactions with blood components. Arteriosclerosis. 1981;1:293-311.

34. Libby P, Friedman GB, Salomon RN. Cytokines as modulators of cell proliferation in fibrotic diseases. Ann Rev Respir Dis. 1989;140:1114-17.

35. Libby $\mathrm{P}$, Hansson GK. Involvement of the immune system in human atherogenesis: current knowledge and unanswered questions. Lab Invest 1991;64:5-15.

36. Fong IW. Antibiotics effects in a rabbit model of Chlamydia pneumoniae-induced atherosclerosis. J Infect Dis 2000;181(Suppl 3):S514-8.

37. Damy S, Higuchi ML, Timenetsky J, et al. Coinfection of laboratory rats with $M y$ coplasma pulmonis and Chlamydia pneumoniae. Contemp Top Lab Anim Sci 2003;42:52-6.

38. Baseman JB, Tully JG. Mycoplasmas: sophisticated reemerging and burdened by their notoriety. Emerging Inf Dis 1997;3:21-32.

39. Chambaud I, Wromblewski H, Blanchard A. Interactions between mycoplasma lipoproteins and the host immune syustem. Trends Microbiol 1999;7:493-9.

40. Baseman JB, Tully JB. Mycoplasmas: sophisticated, re-emerging, and burdened by their notoriety. Emerging Infect Dis. 1997;3:21-32.

41. Maniloff J, McElbaney RN, Finch LR, Baseman JB (ed.). 1992; Mycoplasmas: molecular biology and pathogenesis. American Society for Microbiology, Washington DC 
42. Balse F, Fagetti L, Allegra L. Chlamydia pneumoniae detection in atherosclerotic plaques in Italy. J Infect Dis 2000;181(Suppl 3): S444-6.

43. Maraha B, Berg H, Scheffer GJ, et al. Correlation between detection methods of Chlamydia pneumoniae in atherosclerotic and non-atherosclerotic tissues. Diagn Microbiol Infect Dis 2001;39:139-43.

44. van der Wal AC, Becker AE, van der Loos CM, Tigges AJ, Das PK. Fibrous and lipid-rich atherosclerotic plaques are part of interchangeable morphologies related to inflammation: a concept. Cor Art Dis 1994;5:463-9.

45. Steinberg D. Antioxidants and atherosclerosis. A current assessment. Circulation. 1991;84:1420-5.

46. Fuster V, Gotto AM, Libby P, Loscalzo J, McGill H, Task Force 1. Pathogenesis of coronary disease: The biologic role of risk factors. J Am Coll Cardiol 1996;27:964-1047.

47. Fuster V, Badimon JJ, Chesebro JH, Fallon JT. Plaque rupture, thrombosis, and therapeutic implications. Haemostasis 1996;26(Suppl4):269-84.

48. Berger M, Schroeder B, Daeschlein G, et al. Chlamydia pneumoniae DNA in non-coronary atherosclerotic plaques and circulating leukocytes. J Lab Clin Med 2000;136:194-200

49. Sugiyama S, Okada Y, Sukhova GK, Virmani R, Heinecke JW, Libby P. Macrophage myeloproxidase regulation by granulocyte macrophage colony-stimulating factor in human atherosclerosis and implications in acute coronary syndromes. Am J Pathol 1001;158:879-91.

50. Rikitake Y, Kawashima S, Takeshita S, et al. Anti-oxidative properties of fluvastatin, an HMG-CoA reductase inhibitor, contribute to prevention of atherosclerosis in cholesterol-fed rabbits. Atherosclerosis 2001;154:87-96.

51. Fuhrman B, Aviram M. Flavonoids protect LDL from oxidation and attenuate atherosclerosis. Curr Opin Lipidol 2001;12:41-8

52. Durak I, Kamaz M, Cimen MY, Buyukkocak U, Ozturk HS. Blood oxidant/antioxidant status of atherosclerotic patients. Int J Cardiol 2001;77:293-7.

53. Palinski W, Yl"a-Herttuala S, Rosenfeld ME, et al. Antisera and monoclona antibodies for epitopes generated during the oxidative modification of low density lipoprotein. Arterioscler Thromb 1990;10:325-35.

54. Steinbrecher UP, Fisher M, Witztum JL, Curtiss LK. Immunogenicity of homologous low-density lipoprotein after methilation, ethylation, acetylation, or carbamylation: generation of antibodies specific for derivatized lysine. J Lipid Res. 1984;25:1109-16.

55. Almagor M, Kahane I, Yatziv S. Role of superoxide anion in host cell injury induced by M.pneumoniae infection. A study in normal and trisomy 21 cells. J Clin Invest 1984;73:842-7.

56. Miles RJ, Taylor RR, Varsani H. Oxygen uptake and $\mathrm{H}_{2} \mathrm{O}_{2}$ production by fermentative Mycoplasma spp. J Med Microbiol 1991;34:219-23.

57. Taylor RR, Mohan K, Miles RJ. Diversity of energy-yelding substrates and metabolism in avian mycoplasmas. Vet Microbiol 1996;51:291-304.

58. Ben-Menachem G, Himmelreich R, Herrmann R, Aharonowithz Y, Rottem S. The thiodoxin reductase system of mycoplasmas. Microbiology 1997;143:1933-40.

59. Almagor M, Kahane I, Gilon C, Yatziv S. Protective effects of glutathione redox cycle and vitamin E on cultured fibrobasts infected by Mycoplasma penumoniae. Infect Immun 1986;52:240-4.

60. Chocola J, Strosberg AD, Stanislawski M. Release of hydrogen peroxide from human T cell lines and normal lymphocytes co-infected with HIV-1 and mycoplasma. Free Radic Res 1995;23:197-212.

61. Blanchard A, Montagnier L. AIDS-associated mycoplasmas. Annu Rev Microbiol 1994;48:687-712.

62. Chambaud I, Wroblewski H, Blanchard A. Interactions between mycoplasma lipoproteins and the host immune system. Trends Microbiol 1999;7:493-9.

63. Faulkner CB, Simecka JW, Davidson MK, et al. Gene expression and production of TNF $\alpha$, IL-1, IL-6 and IFN- $\gamma$ in acute Mycoplasma pulmonis disease. Infect Immun 1995;63:4084-90.

64. Pietsch K, Ehlers S, Jacobs E. Cytokine gene expression in the lungs of BALB/c mice during primary and secondary intranasal infection with Mycoplasma pneumoniae. Microbiology 1994;140:2043-8.

65. Izutsu KT, Fatherazi S, Belton CM, Oda D, Cartwright FD, Kenny GE. Mycoplasma orale infection affects $\mathrm{K}+$ and $\mathrm{Cl}$ - currents in the HSG salivary fland cell line. In Vitro Cell Dev Biol Anim 1996;32:361-5.

66. Matsui M, Kobayashi M, Mitsup Y. Elevation of endothelin biosynthesis in human endothelial cells with mycoplasma infection. In Vitro Cell Dev Biol Anim 1995;31:880-5.

67. Rawadi G, Roman-Roman S, Castedo M, et al. Effects of Mycoplasma fermentans on the myelomonocytic lineage. Different molecular entities with cytokineinducing and cytocidal potential. J Immunol 1996;156:670-8.

68. Shibata K, Watanabe T. Mycoplasma fermentans enhances concavalin A-induced apoptosis of mouse splenic T cells. FEMS Immunol Med Microbiol 1997; 17:103-9.

69. Sasaki Y, Cunha RA, Gougeon L, Montagnier L, Blanchard A. Mycoplasma penetrans cytopathic effects: an in vitro study using human peripheral blood mononuclear cells. IOM Lett. 1996;4:6-7.

70. Grau O, Slizewicz B, Tuppin P, et al. Association of Mycoplasma penetrans with human immunodeficiency virus infection. J Infect Dis 1995;172:672-81.

71. Lapidot Z, Naot Y. Immunohistochemical characterization of Mycoplasma pulmonis membrane mitogens. IOM Lett 1996;4:385.

72. Tsai S, Wear DJ, Shih JW, Lo SC. Mycoplasma and oncogenesis: persistent infection and multistage malignant transformation. Proc Natl Acad Sci 92:10197-201.

73. Fan T, Lu H, Hu H, et al. Inhibition of apoptosis in chlamydia-infected cells: blockade of mitochondrial cytochrome c release and caspase activation. J Exp Med 1998; 187(4): 487-96.

74. Murry CE, Gipaya CT, Bartosek T, Benditt EP, Schwartz SM. Monoclonality of smooth muscle cells in human atherosclerosis. Am J Pathol 1997;151:697-705.

75. Schwartz SM, Majesky MW, Murry CE. The intima: development and monoclonal responses to injury. Atheroslcerosis 1995;118:S125-40.

76. Meijer A, van der Vliet JAQ, Roholl PJ, Gielis-Porper SK, de Vries A, Ossewaarde JM. Chlamydia pneumoniae in abdominal aortic aneurysms: abundance of membrane components in the absence of heat shock protein 60 and DNA. Arterioscler Thromb Vasc Biol 1999;19:2680-6.

77. Mallat Z, Hugel B, Ohan J, Leseche G, Freyssinet JM, Tedgui A. Shed membrane microparticles with procoagulant potential in human atherosclerotic plaques: a role for apoptosis in plaque thrombogenicity. Circulation 1999;99:348-53.

78. Fong IW, Chiu B, Viira E, Jang D, Mahony JB. De Novo induction of atherosclerosis by Chlamydia pneumoniae in a rabbit model. Infect Immun 1999;67: 6048-55. 